\title{
Editorial
}

\section{Body Dysmorphic Disorder: Common, Severe and in Need of Treatment Research}

\author{
Katharine A. Phillips \\ Rhode Island Hospital, and Department of Psychiatry and Human Behavior, Alpert Medical School of \\ Brown University, Providence, R.I., USA
}

Body dysmorphic disorder (BDD) is common yet very under-recognized. It has a point prevalence of about $2 \%$, making it more common than obsessive-compulsive disorder (OCD), anorexia nervosa or schizophrenia [1]. BDD typically causes tremendous suffering and substantial impairment in psychosocial functioning. The rates of suicidal ideation, suicide attempt and completed suicide appear markedly high. Yet treatment research on BDD lags very far behind that of other common and severe disorders. Thus, the study by Veale et al. [2] is a major contribution to the literature and to patient care.

Individuals with BDD (previously known as 'dysmorphophobia') are preoccupied with one or more perceived defects or flaws in their appearance; these defects, however, are not observable or appear only slight to others (DSM-5 criterion A) [1]. Preoccupations most often focus on skin (e.g. perceived acne, scarring, wrinkles, color), nose (e.g. size or asymmetry) and hair (e.g. too little hair) but may focus on any body area [3]. Patients typically describe the disliked body parts as 'ugly', 'unattractive', 'hideous', or even 'monstrous'. The preoccupations occur, on average, for 3-8 h a day (usually for at least an hour a day). They are intrusive, unwanted, and usually difficult to resist and control $[4,5]$.

\section{KARGER}

(C) 2014 S. Karger AG, Basel

0033-3190/14/0836-0325\$39.50/0

E-Mail karger@karger.com

www.karger.com/pps
The appearance preoccupations trigger feelings of depression, anxiety, distress, shame, or other painful emotions. These emotions, in turn, trigger repetitive compulsive behaviors that are intended to alleviate the emotional distress [5]. As required by DSM-5 criterion B (which is new to DSM-5), all individuals with BDD perform excessive repetitive behaviors in response to the preoccupations with appearance at some time during the course of the disorder [1]. These repetitive behaviors have many similarities to OCD compulsions, and thus they are commonly referred to as compulsions or rituals. Common excessive behaviors include checking mirrors, excessive grooming, seeking reassurance about the perceived defects, skin picking (to try to minimize perceived blemishes), and tanning (e.g. to darken 'pale' skin) [3]. Some BDD compulsions consist of mental acts, such as comparing one's own appearance with that of other people, rather than observable behaviors [3]. The repetitive behaviors are difficult to control and occur, on average, for $3-8 \mathrm{~h}$ a day $[4,5]$. Nearly all patients camouflage the perceived defects (e.g. with a hat, makeup, hair, clothes, body position). Although camouflaging is a safety behavior, it can also be done repeatedly (e.g. reapplying makeup 20 times a day), in which case it may be considered a repetitive behavior [3]. 
To meet DSM-5 BDD criteria, the appearance preoccupations and resulting repetitive behaviors must cause clinically significant distress or impairment in social, occupational or other important areas of functioning [1]. On standardized measures of these constructs, individuals with BDD typically score several standard deviation units below normative scores [6]. More severe BDD symptoms are associated with poorer functioning and quality of life [6]. Some patients experience only moderate functional impairment because of BDD (e.g. they may avoid only some social interactions and have difficulty concentrating at work but are able to remain employed), whereas many experience severe or extreme impairment in functioning (e.g. dropping out of school, being unable to work, having no relationships, or being housebound because of BDD) $[3,5,6]$.

According to DSM-5, if appearance preoccupations involve only excessive body fat or weight, and the patient has an eating disorder diagnosis, the fat or weight concerns should be diagnosed as an eating disorder rather than BDD [1]. However, BDD (consisting of concerns with other body areas) and eating disorders commonly co-occur [3].

Once the clinician has diagnosed BDD, he/she should consider the following two specifiers, which are new to DSM-5 and identify important subgroups of individuals with BDD:

(1) Muscle dysmorphia: this specifier identifies individuals (usually men) who are preoccupied with the belief that their body build is too small or insufficiently muscular, even though they look normal or even very muscular because of excessive weight lifting or anabolic steroid use $[1,4]$. This specifier is used even if a patient has additional, nonmuscle-focused preoccupations, which is usually the case.

(2) Insight: this specifier indicates the level of insight regarding BDD beliefs (e.g. 'I look ugly'). Levels of insight in DSM-5 are 'with good or fair insight', 'with poor insight', and 'with absent insight/delusional beliefs'. This new insight specifier in DSM-5 is important for several reasons [7]: (i) it clarifies that individuals who are completely convinced that their BDD belief is true should be diagnosed with 'BDD with absent insight/delusional beliefs' rather than a psychotic disorder; (ii) it implies that delusional and nondelusional BDD should be treated similarly - indeed, studies indicate that both delusional and nondelusional BDD respond to serotonin reuptake inhibitor (SRI) monotherapy and to cognitive-behavioral therapy (CBT), and (iii) specifying the level of insight allows the iden- tification of patients with poorer insight, who may be more reluctant to accept the idea that they have a mental disorder (BDD) rather than actual physical deformities. Such patients may need more motivational interviewing and attention to the therapeutic alliance in order to engage and retain them in mental health treatment.

The rates of suicidal ideation and suicide attempts are very high in adults and youth with $\mathrm{BDD}$; greater $\mathrm{BDD}$ severity independently predicts greater suicidal ideation and suicide attempts [8-10]. Although completed suicide in $\mathrm{BDD}$ has been only minimally studied, the rate appears markedly elevated and may be even higher than that in other serious mental disorders such as bipolar disorder and major depressive disorder [10].

What do patients with BDD actually see? We have no firm answers to this intriguing question. However, emerging evidence suggests that individuals with BDD actually see things differently than those without BDD. People with BDD appear to have abnormalities in visual processing that consist of a bias for encoding and analyzing details of faces and nonfacial objects (such as houses or complex figures) rather than using holistic visual processing strategies (i.e. seeing 'the big picture') $[11,12]$. Preliminary data also suggest abnormalities in executive functioning [13], increased total white matter volume [14] and compromised white matter fibers (reduced organization) and inefficient connections between different brain areas, which is associated with poorer BDD-related insight $[15,16]$. However, studies are few, and some findings are inconsistent across studies. Individuals with BDD also appear to have difficulty identifying emotional facial expressions and a bias toward interpreting neutral faces and scenarios as threatening (consistent with BDDrelated ideas/delusions of reference) [17]. Preliminary data suggest that past teasing and high rates of childhood neglect and/or abuse are also associated with BDD [18, 19]. Taken together, these emerging findings indicate that, like other psychiatric disorders, the etiology/pathophysiology of BDD is likely to be multifactorial and complex. In addition, these findings indicate that BDD is a brain-based disorder - not vanity.

Perhaps the most important question for clinicians is how can we successfully treat these very ill patients, and why is a separate treatment needed? Why not just treat $\mathrm{BDD}$ as if it were OCD, social anxiety disorder, major depressive disorder, or schizophrenia? The reason is that BDD differs in some important ways from its 'nearneighbor disorders' - e.g. in terms of clinical features and treatment response $[5,20]$. Although it is likely that $\mathrm{BDD}$ 
is related to OCD (e.g. BDD is more common in firstdegree relatives of OCD probands than control probands, suggesting shared etiology/pathophysiology [21]), BDD is characterized by greater comorbidity with major depressive disorder, greater suicidality, poorer insight, and information-processing differences $[5,20,22]$. In addition, clinical experience indicates that simply treating $\mathrm{BDD}$ with exposure and response prevention for $\mathrm{OCD}$ or another disorder is unlikely to be successful.

Thus, it is important to accurately diagnose BDD and to implement treatment for BDD specifically. Measures are available to screen for, diagnose, and assess the severity of BDD and to assess insight in BDD (www.bodyimageprogram.com) [23-26].

A few basics about treatment are as follows: (1) because BDD-related insight is usually absent or poor, motivational interviewing is often needed to encourage patients to accept and remain in mental health treatment; (2) focusing on patients' suffering and functional impairment rather than trying to convince them that they actually look normal, which they usually do not accept because their insight is typically poor or absent, may help them agree to mental health treatment, and (3) patients should be discouraged from getting dermatological, surgical, dental, and other cosmetic treatments for BDD concerns. Available data suggest that cosmetic treatment is almost never effective for $\mathrm{BDD}$, can make symptoms worse, and can trigger legal action or even violent behavior towards clinicians who provide such treatment [2729].

CBT is currently considered the psychotherapy of choice for BDD [5]. Case series and three studies that used a wait-list control group found that BDD-focused CBT (an additional study used metacognitive therapy) is often efficacious and that subjects improve more with CBT than with no treatment [30-33]. However, this type of control group does not control for therapist time and attention, and thus the study by Veale et al. [2] is of particular importance. This study found that BDD-focused CBT was more efficacious for BDD than anxiety management after 12 weeks of treatment. Outcomes improved even further after 4 additional CBT sessions, and gains were maintained at the 1-month follow-up. Importantly, CBT was as efficacious for participants with delusional $\mathrm{BDD}$ as for those with nondelusional BDD.

Two CBT treatment manuals with some published evidence to support their efficacy are now available for therapists to use when treating $\mathrm{BDD}[34,35]$. Their effectiveness has not been compared, but the good news for patients is that if one manual is not adequately helpful, the other may be. Because BDD can be difficult to treat, and because its treatment differs in important ways from that of other disorders, the use of a treatment manual is highly recommended for all patients with BDD, especially those with more severe BDD.

The study by Veale et al. [2] has many methodological strengths, including the use of a therapy control group, evaluators of treatment outcome who were blinded to treatment conditions, and equally credible treatments. However, this study (like all studies) has some limitations. One is the brief duration of treatment - only 12 weeks for the controlled portion of the study, and only 16 weeks for the total duration of CBT. Many published studies used a longer treatment, e.g. weekly treatment for 24 weeks [30] or even as many as $90 \mathrm{~h}$ of treatment [36], reflecting how ill and impaired many patients are; patients continue to further improve with treatment after 12 or 16 weeks [30]. It is likely that the finding of Veale et al. [2] that only $48 \%$ of patients responded to CBT after 12 weeks reflects the brief treatment duration and the need for longer treatment. An important question is whether treatment gains are maintained for longer than a month, as was found by Veale et al.; other studies have found that this is often the case $[30,37]$.

It should be mentioned that SRIs are also often efficacious for BDD; they are currently considered the first-line somatic treatment for BDD $[5,38]$. Two blinded controlled trials $[39,40]$ and four methodologically rigorous open-label trials indicated that SRIs are efficacious for the majority of patients with BDD [38]. Importantly, SRIs may protect against worsening of suicidality and decrease suicidal ideation in individuals with BDD [41, 42]. SRIs appear more efficacious than non-SRI antidepressants or other types of psychotropic medication [5, $38,39]$. However, data are limited, and published efficacy trials are limited to acute trials of no more than 16 weeks. SRI monotherapy appears as efficacious for patients with delusional BDD beliefs as for those with nondelusional beliefs [5, 38-40].

Although rigorous dose-finding studies are lacking, effective SRI doses needed to successfully treat BDD appear to often be substantially higher than those typically needed to treat many other disorders such as depression $[5,38]$. Not uncommonly, response is optimized when the maximum SRI dose recommended by the manufacturer is exceeded (although this dose should not be exceeded for clomipramine or citalopram) $[5,38]$. To determine if an SRI is efficacious, patients should receive a trial of 12-16 weeks, while reaching a high dose (if needed and tolerated) for at least 3-4 of those weeks $[5,38]$. 
Small open-label trials suggest that the SNRI venlafaxine and the antiepileptic medication levetiracetam may be helpful for BDD; however, these medications are not currently recommended as first-line treatments for BDD [5, 38]. The use of medications should be considered within a broader framework of their potential benefits and adverse effects [43].

In summary, the CBT study by Veale et al. [2] (in this issue) is a substantial and meaningful contribution to the literature and should encourage the use of BDD-focused CBT for BDD. However, additional treatment development and efficacy studies are urgently needed, including larger CBT studies, CBT studies with control groups that receive treatments commonly used in the community (e.g. supportive psychotherapy), studies of CBT augmentation of SRIs and vice versa, and studies of other psychotherapies, non-SRI medications, and other somatic treatments. Treatment studies in youth are especially needed; two thirds of individuals with BDD have an onset of the disorder before the age of 18 , yet no manualized psychosocial treatment is available for youth with BDD [44]. BDD is common enough and severe enough that such studies should be done. Without appropriate treatment, BDD is usually chronic and associated with substantial morbidity and mortality $[10,45,46]$.

\section{References}

1 American Psychiatric Association: Diagnostic and Statistical Manual of Mental Disorders, ed 5. Arlington, American Psychiatric Association, 2013.

-2 Veale D, Anson M, Miles S, Pieta M, Costa A, Ellison N: Efficacy of cognitive behaviour therapy versus anxiety management for body dysmorphic disorder: a randomised controlled trial. Psychother Psychosom, in press.

-3 Phillips KA, Menard W, Fay C, Weisberg R: Demographic characteristics, phenomenology, comorbidity, and family history in 200 individuals with body dysmorphic disorder. Psychosomatics 2005;46:317-325.

4 Phillips KA, Wilhelm S, Koran LM, Didie ER, Fallon BA, Feusner J, Stein DJ: Body dysmorphic disorder: some key issues for DSM-V. Depress Anxiety 2010;27:573-591.

5 Phillips KA: Understanding Body Dysmorphic Disorder: An Essential Guide. New York, Oxford University Press, 2009.

6 Phillips KA, Menard W, Fay C, Pagano ME: Psychosocial functioning and quality of life in body dysmorphic disorder. Compr Psychiatry 2005;46:254-260.

7 Phillips KA: Delusional versus nondelusional body dysmorphic disorder: recommendations for DSM-5. CNS Spectr 2014;19:10-20.

8 Phillips KA, Coles M, Menard W, Yen S, Fay C, Weisberg RB: Suicidal ideation and suicide attempts in body dysmorphic disorder. J Clin Psychiatry 2005;66:717-725.

-9 Buhlmann U, Glaesmer H, Mewes R, Fama JM, Wilhelm S, Brahler E, Rief W: Updates on the prevalence of body dysmorphic disorder: a population-based survey. Psychiatry Res 2010;178:171-175.

10 Phillips KA, Menard W: Suicidality in body dysmorphic disorder: a prospective study. Am J Psychiatry 2006;163:1280-1282.

$\checkmark 11$ Feusner JD, Townsend J, Bystritsky A, Bookheimer S: Visual information processing of faces in body dysmorphic disorder. Arch Gen Psychiatry 2007;64:1417-1425.
12 Feusner JD, Hembacher E, Moller H, Moody TD: Abnormalities of object visual processing in body dysmorphic disorder. Psychol Med 2011;41:2385-2397.

13 Dunai J, Labuschagne I, Castle DJ, Kyrios M, Rossell SL: Executive function in body dysmorphic disorder. Psychol Med 2010;40: 1541-1548.

14 Rauch SL, Phillips KA, Segal E, Makris N, Shin LM, Whalen PJ, Jenike MA, Caviness VS Jr, Kennedy DN: A preliminary morphometric magnetic resonance imaging study of regional brain volumes in body dysmorphic disorder. Psychiatry Res 2003;20;122:13-19.

15 Feusner JD, Arienzo D, Li W, Zhan L, Gad Elkarim J, Thompson PM, Leow AD: White matter microstructure in body dysmorphic disorder and its clinical correlates. Psychiatry Res 2013;211:132-140.

16 Buchanan BG, Rossell SL, Maller JJ, Toh WL, Brennan S, Castle DJ: Brain connectivity in body dysmorphic disorder compared with controls: a diffusion tensor imaging study. Psychol Med 2013;43:2513-2521.

17 Buhlmann U, Etcoff NL, Wilhelm S: Emotion recognition bias for contempt and anger in body dysmorphic disorder. J Psychiatr Res 2006;40:105-111.

18 Buhlmann U, Cook LM, Fama JM, Wilhelm $S$ : Perceived teasing experiences in body dysmorphic disorder. Body Image 2007;4:381385.

19 Didie ER, Tortolani CC, Pope CG, Menard W, Fay C, Phillips KA: Childhood abuse and neglect in body dysmorphic disorder. Child Abuse Negl 2006;30:1105-1115.

20 Phillips KA, Stein DJ, Rauch SL, Hollander E, Fallon BA, Barsky A, Fineberg N, MataixCols D, Ferrao YA, Saxena S, Wilhelm S, Kelly MM, Clark LA, Pinto A, Bienvenu OJ, Farrow J, Leckman J: Should an obsessive-compulsive spectrum grouping of disorders be included in DSM-V? Depress Anxiety 2010; 27:528-555.
21 Bienvenu OJ, Samuels JF, Wuyek LA, Liang KY, Wang Y, Grados MA, Cullen BA, Riddle MA, Greenberg BD, Rasmussen SA, Fyer AJ, Pinto A, Rauch SL, Pauls DL, McCracken JT, Piacentini J, Murphy DL, Knowles JA, Nestadt G: Is obsessive-compulsive disorder an anxiety disorder, and what, if any, are spectrum conditions? A family study perspective. Psychol Med 2012;42:1-13.

22 Phillips KA, Pinto A, Menard W, Eisen JL, Mancebo M, Rasmussen SA: Obsessive-compulsive disorder versus body dysmorphic disorder: a comparison study of two possibly related disorders. Depress Anxiety 2007;24: 399-409.

23 First MB, Spitzer RL, Gibbon M, Williams JBW: The Structured Clinical Interview for DSM-IV Axis I Disorders, Patient Edition. New York, New York Psychiatric Institute, 1995.

24 Phillips KA. The Broken Mirror: Understanding and Treating Body Dysmorphic Disorder. New York, Oxford University Press, 2005.

25 Phillips KA, Hollander E, Rasmussen SA, Aronowitz BR, DeCaria C, Goodman WK: A severity rating scale for body dysmorphic disorder: development, reliability, and validity of a modified version of the Yale-Brown Obsessive-Compulsive Scale. Psychopharmacol Bull 1997;33:17-22.

26 Eisen JL, Phillips KA, Baer L, Beer DA, Atala KD, Rasmussen SA: The Brown Assessment of Beliefs Scale: reliability and validity. Am J Psychiatry 1998;155:102-108.

27 Phillips KA, Grant J, Siniscalchi J, Albertini RS: Surgical and nonpsychiatric medical treatment of patients with body dysmorphic disorder. Psychosomatics 2001;42:504-510.

28 Crerand C, Phillips KA, Menard W, Fay C: Non-psychiatric medical treatment of body dysmorphic disorder. Psychosomatics 2005; 46:549-555. 
29 Sarwer DB: Awareness and identification of body dysmorphic disorder by aesthetic surgeons: results of a survey of American Society for Aesthetic Plastic Surgery members. Aesthet Surg J 2002;22:531-535.

30 Wilhelm S, Phillips KA, Didie E, Buhlmann U, Greenberg JL, Fama JM, Keshaviah A, Steketee G: Modular cognitive-behavioral therapy for body dysmorphic disorder: a randomized controlled trial. Behav Ther 2013;45: 314-327.

-31 Veale D, Gournay K, Dryden W, Boocock A, Shah F, Willson R, Walburn J: Body dysmorphic disorder: a cognitive behavioural model and pilot randomised controlled trial. Behav Res Ther 1996;34:717-729.

-32 Rosen JC, Reiter J, Orosan P: Cognitive-behavioral body image therapy for body dysmorphic disorder. J Consult Clin Psychol 1995;63:263-269.

33 Rabiei M, Mulkens S, Kalantari M, Molavi H, Bahrami F: Metacognitive therapy for body dysmorphic disorder patients in Iran: acceptability and proof of concept. J Behav Ther Exp Psychiatry 2012;43:724-729.
34 Veale D, Neziroglu F: Body Dysmorphic Disorder: A Treatment Manual. Chichester, Wiley-Blackwell, 2010.

35 Wilhelm S, Phillips KA, Steketee G: Cognitive-Behavioral Therapy for Body Dysmorphic Disorder: A Treatment Manual. New York, Guilford Press, 2013.

36 Neziroglu FA, Yaryura-Tobias JA: Exposure, response prevention, and cognitive therapy in the treatment of body dysmorphic disorder. Behav Ther 1993;24:431-438.

37 McKay D: Two-year follow-up of behavioral treatment and maintenance for body dysmorphic disorder. Behav Modif 1999;23:620-629.

38 Phillips KA, Hollander E: Treating body dysmorphic disorder with medication: evidence, misconceptions, and a suggested approach. Body Image 2008;5:13-27.

39 Hollander E, Allen A, Kwon J, Aronowitz B, Schmeidler J, Wong C, Simeon D: Clomipramine vs desipramine crossover trial in body dysmorphic disorder: selective efficacy of a serotonin reuptake inhibitor in imagined ugliness. Arch Gen Psychiatry 1999;56:10331039.

40 Phillips KA, Albertini RS, Rasmussen SA: A randomized placebo-controlled trial of fluoxetine in body dysmorphic disorder. Arch Gen Psychiatry 2002;59:381-388.
1 Phillips KA: An open-label study of escitalopram in body dysmorphic disorder. Int Clin Psychopharmacol 2006;21:177-179.

42 Phillips KA, Kelly MM: Suicidality in a placebo-controlled fluoxetine study of body dysmorphic disorder. Int Clin Psychopharmacol 2009;24:26-28.

43 Fava GA: Rational use of antidepressant drugs. Psychother Psychosom 2014;83:197204.

44 Bjornsson AS, Didie ER, Grant JE, Menard W, Stalker E, Phillips KA: Age at onset and clinical correlates in body dysmorphic disorder. Compr Psychiatry 2013;54:893-903.

45 Phillips KA, Menard W, Quinn E, Didie ER, Stout RL: A 4-year prospective observational follow-up study of course and predictors of course in body dysmorphic disorder. Psychol Med 2013;43:1109-1117.

-46 Phillips KA, Quinn G, Stout RL: Functional impairment in body dysmorphic disorder: a prospective, follow-up study. J Psychiatr Res 2008;42:701-707. 